\title{
A Study on Marble-Based Geopolymer
}

\author{
Ta-Wui Cheng ${ }^{1, *}$, Yung-Chin Ding ${ }^{1}$, Wei-Hao Lee ${ }^{1}$, and Po-chang Lu ${ }^{1}$ \\ ${ }^{1}$ Institute of Mineral Resources Engineering, National Taipei University of Technology, Taipei City, \\ Da'an Dist., 106, Taiwan, R.O.C.
}

\begin{abstract}
Cement manufacturing is one of the highest carbon dioxide emission industries. It releases $880 \mathrm{~kg}$ carbon dioxide for every ton of cement produced. In Taiwan, the carbon dioxide emission from cement industry is more than 10 million tons per year. The development of low carbon dioxide emission green cement can be a solution to replace part of OPC for civil applications and reduce carbon dioxide emission. Geopolymer consists of a polymeric $\mathrm{Si}-\mathrm{O}-\mathrm{Al}$ framework, similar to zeolites which can be formed by mixing aluminosilicate materials, sodium hydroxide and sodium silicates. Geopolymers have advantage of high compressive strength, fire resistance, low shrinkage, acid resistance and low thermal conductivity. In this study, marble-based geopolymer was studied by mixing marble powder, blast furnace slag (BFS) and alkali solution. Physical/mechanical properties of marble-based geopolymer prepared with different marble/BFS weight ratio and $\mathrm{SiO}_{2} / \mathrm{Na}_{2} \mathrm{O}$ mole ratio were tested. The experimental results indicated that the compressive strength of marble-based geopolymer can reach $44 \mathrm{MPa}$ within 120 minutes setting time. The microstructure of geopolymeric green cement contains C-S-H gel and aluminosilicate in the framework. According to the experiment results, marble-based geopolymer has the potential to be used as a new civil engineering construction material.
\end{abstract}

\section{Introduction}

According to International Energy Agency IEA/OECD statistics in 2015, energy related carbon dioxide emissions was over 248.7 million tonnes in Taiwan and ranked No. 22 in the world's [4]. Therefore, the reduction of carbon dioxide emissions has become a very important issue to alleviate the problem. It is well known that the production of OPC emits large quantity of carbon dioxide [1]. Cement manufacturing is one of the highest carbon dioxide emission industries. It releases $880 \mathrm{~kg}$ carbon dioxide for every ton of cement produced. The annual global cement production has reached 2.8 billion tonnes [5]. The OPC production contributes approximately 5-8\% of global $\mathrm{CO}_{2}$ emissions [6]. Geopolymer is a three-dimensional framework aluminosilicate material [2], and is an inorganic non-metallic material newly developed in recent years. In comparision with Portland cement production, the carbon dioxide emission of geopolymer is extremely low. It has very good characteristics, such as early compressive strength, durability, fire resistance, immobilization of heavy metals, etc. [3]. Previous studies have presented when

\footnotetext{
* Corresponding author : twcheng@ntut.edu.tw
} 
using geopolymeric technology to make geopolymer could reduce over $80 \%$ carbon dioxide emission. In this study, marble and blast furnace slag (BFS) were used as raw materials to fabricate marble-based geopolymer under the activation of alkaline solutions of various molar ratios at ambient condition. The characteristics of marble-based geopolymer in workability (viscosity, setting time), compressive strength and ${ }^{29} \mathrm{Si}$ NMR analysis were presented in this study.

\section{Experimental}

The marble samples used in this study were collected from a marble mine in eastern Taiwan. The BFS samples were produced from China Steel in southern Taiwan. The chemical composition of marble and BFS were analyzed by X-ray fluorescence (XRF), as listed in Table 1.The major composition in marble and blast furnace slag was calcium oxide, however, the blast furnace slag also contains $27.7 \%$ of $\mathrm{SiO}_{2}$. Alkali solution was prepared by mixing $\mathrm{NaOH}$ and Sodium silicate, and the $\mathrm{SiO}_{2} / \mathrm{Na}_{2} \mathrm{O}$ molar ratio was controlled at $0.96,1.28$, and 1.40 . The experimental procedure and test parameters were shown in Figure 1 and Table 2.

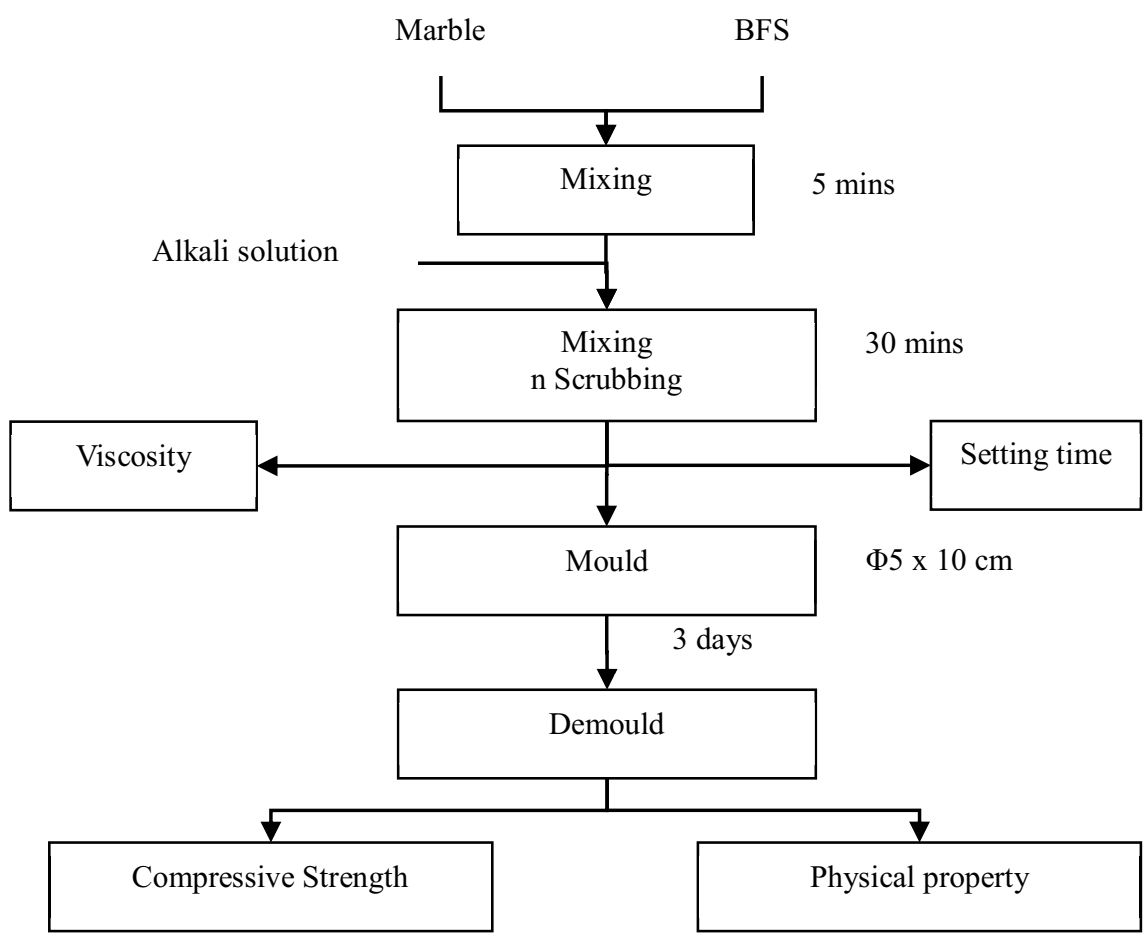

Fig. 1. Overall experiment procedures

Table 1. Marble \& Blast furnace slag Chemical Composition

\begin{tabular}{|c|c|c|c|c|c|c|}
\hline Composition & $\mathrm{SiO}_{2}$ & $\mathrm{CaO}$ & $\mathrm{Al}_{2} \mathrm{O}_{3}$ & $\mathrm{Fe}_{2} \mathrm{O}_{3}$ & L.O.I. & Other \\
\hline warble & 1.3 & 63.9 & 1.3 & 0.2 & 28.0 & 5.3 \\
\hline Blast furnace slag & 27.7 & 57.9 & 1.2 & 0.4 & - & 2.8 \\
\hline
\end{tabular}


Table 2. Experiment Parameters

\begin{tabular}{|c|c|c|c|c|c|}
\hline \multirow{2}{*}{$\begin{array}{l}\text { Experiment } \\
\text { No. }\end{array}$} & \multicolumn{2}{|c|}{$\begin{array}{c}\text { Solid Materials } \\
\text { wt.\% }\end{array}$} & Alkali Solution & \multirow{2}{*}{$\begin{array}{l}\text { Liquid / Solid } \\
\text { wt.\% ratio }\end{array}$} & \multirow{2}{*}{$\begin{array}{l}\text { Viscosity } \\
(\mathrm{mPa} \cdot \mathrm{s})\end{array}$} \\
\hline & Marble & BFS & $\mathrm{SiO}_{2} / \mathrm{Na}_{2} \mathrm{O}$ & & \\
\hline M5S5 & 50 & 50 & \multirow{6}{*}{1.28} & \multirow{4}{*}{0.4} & 2900 \\
\hline M6S4 & 60 & 40 & & & 2000 \\
\hline M7S3 & \multirow{7}{*}{70} & \multirow{7}{*}{30} & & & 1100 \\
\hline M7S3-LS040 & & & & & 1100 \\
\hline M7S3-LS038 & & & & 0.38 & 2200 \\
\hline M7S3-LS035 & & & & 0.35 & 5500 \\
\hline M7S3A096 & & & 0.96 & \multirow{3}{*}{0.4} & 6700 \\
\hline M7S3A128 & & & 1.28 & & 1100 \\
\hline M7S3A140 & & & 140 & & 1800 \\
\hline
\end{tabular}

\section{Results and Discussion}

\subsection{Effect of marble/BFS ratio}

The effect of marble/BFS ratio on setting time and compressive strength of cement mortar are illustrated in Figure 2. The initial and final setting time increases as the amount of BFS decreases. Because BFS has higher reactivity than marble, the setting time of geopolymer paste can be increased by increasing the amount of BFS in the marble BFS mixture. The compressive strength of marble-based geopolymer was also affected by the mixing ratio of marble and BFS. As shown in Figure 2, the compressive strength of cement mortar increases as the amount of BFS increase. However, micro cracks on geopolymer specimen was observed if the amount of BFS is over $40 \%$, and thus, resulted in the compressive strength reduction of marble-based geopolymer. According to the experiment results, while using marble and blast furnace slag at the $\mathrm{Wt} \%$ ratio of $7: 3$ to form geopolymer, the final setting time of geopolymer paste was around $120 \mathrm{mins}$, and the viscosity was $1100 \mathrm{mPa} \cdot \mathrm{s}$. The compressive strength can reache $42 \mathrm{MPa}$ after curing for 28 days.

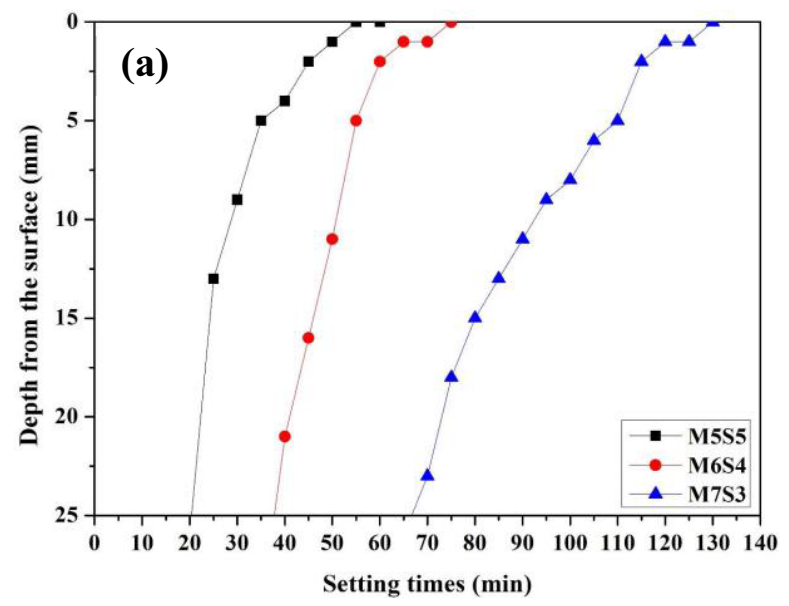




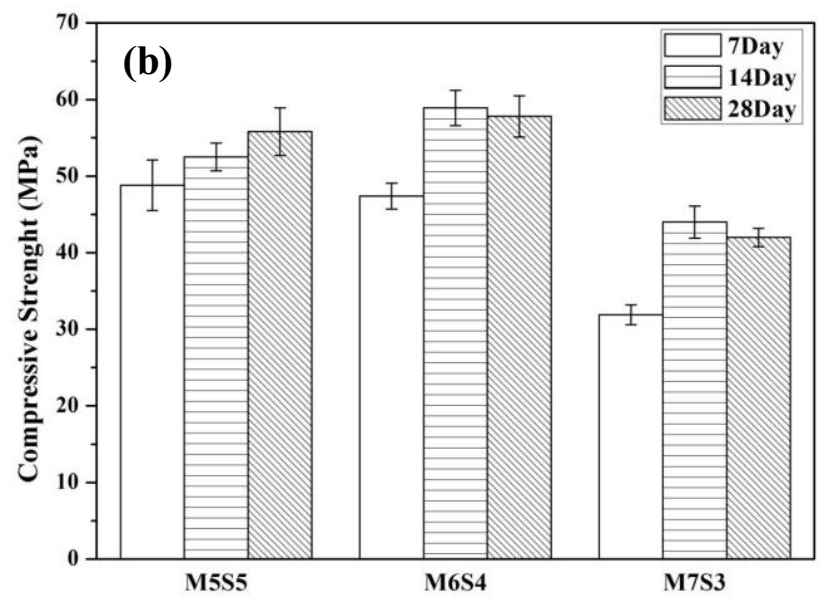

Fig. 2. Effect of marble/BFS ratio for (a) Setting time (b) Compressive strength (Alkali Solution $\mathrm{SiO}_{2} / \mathrm{Na}_{2} \mathrm{O}=1.28, \mathrm{~L} / \mathrm{S}=0.4$ )

\subsection{Effect of Alkali solution/solid materials ratio (L/S ratio)}

The effect of L/S ratio on setting time and compressive strength are shown in Figure 3. It was found that the initial and final setting time of geopolymers were strongly affected by the liquid/solid ratio, when the amount of alkali solution increased, the viscosity of geopolymer paste rapidly reduced, and caused the setting time increased. The compressive strength of marble based geopolymer was also affected by the alkali solution/solid materials ratio. Geopolymer compressive strength increased while decreasing L/S ratio. The optimal parameter for higher compressive strength result was the test samples of M7S3-LS035, but the initial and final setting time of M7S3-LS035 and M7S3-LS038 was too fast, their workability were unsatisfactory.

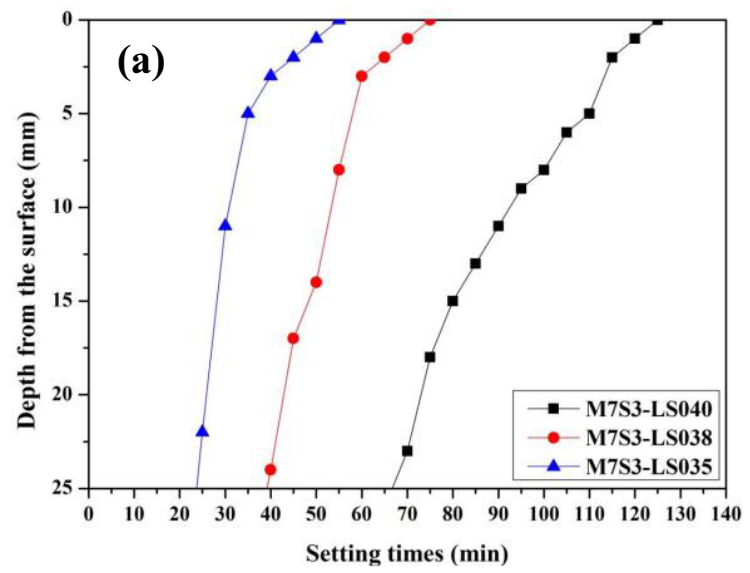




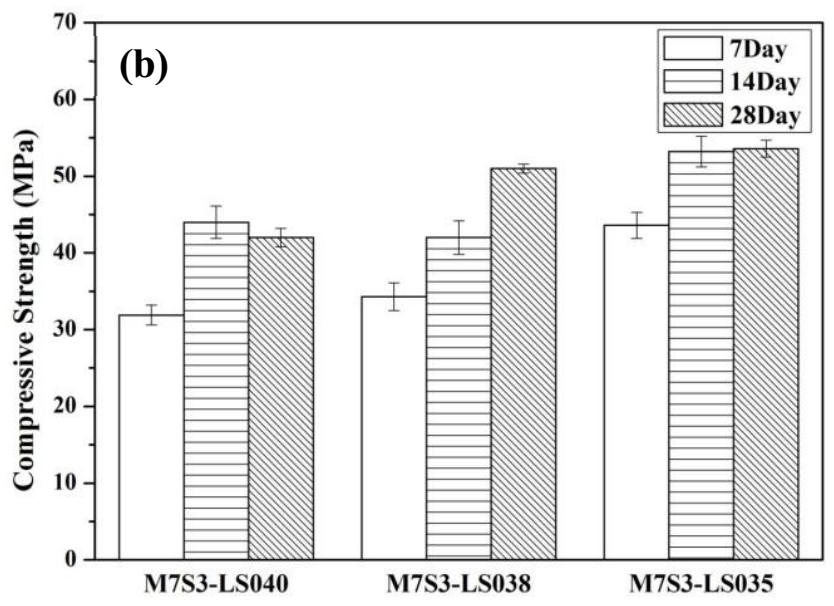

Fig. 3. The effect of Alkali solution/solid materials ratio for (a) Setting time (b) Compressive strength (Alkali Solution $\mathrm{SiO}_{2} / \mathrm{Na}_{2} \mathrm{O}=1.28$, Marble / BFS wt.\% ratio $=70: 30$ )

\subsection{Effect of $\mathrm{SiO}_{2} / \mathrm{Na}_{2} \mathrm{O}$ molar ratio}

The effect of $\mathrm{SiO}_{2} / \mathrm{Na}_{2} \mathrm{O}$ molar ratio for setting time and compressive strength are shown in Figure 4. As $\mathrm{SiO}_{2} / \mathrm{Na}_{2} \mathrm{O}$ molar ratio was higher or lower than 1.28 , the initial and final setting time was reduced. Generally, the compressive strength increases as the curing days extends. After curing for 28 days, the compressive strength of all samples can reach 40 $\mathrm{MPa}$ and above. By considering the workability of geopolymer, using alkali solution with $\mathrm{SiO}_{2} / \mathrm{Na}_{2} \mathrm{O}$ molar ratio $=1.28$ is the optimal value.

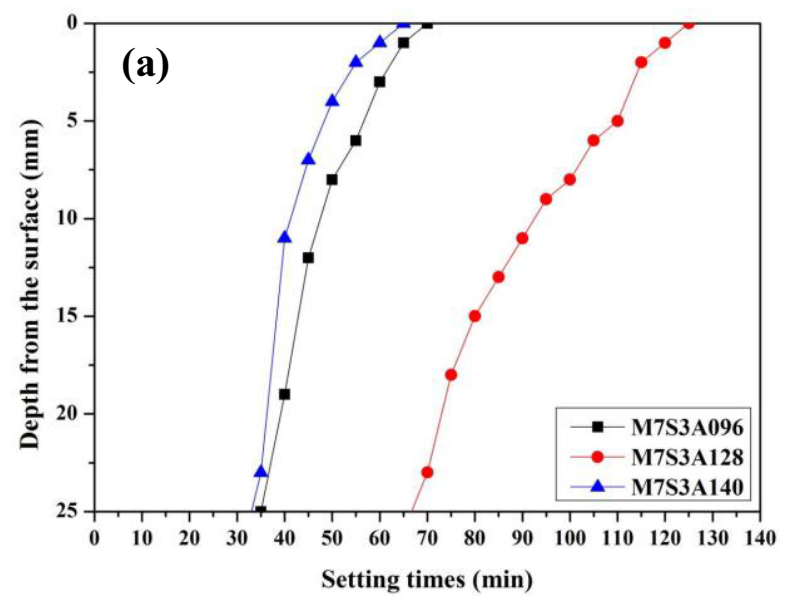




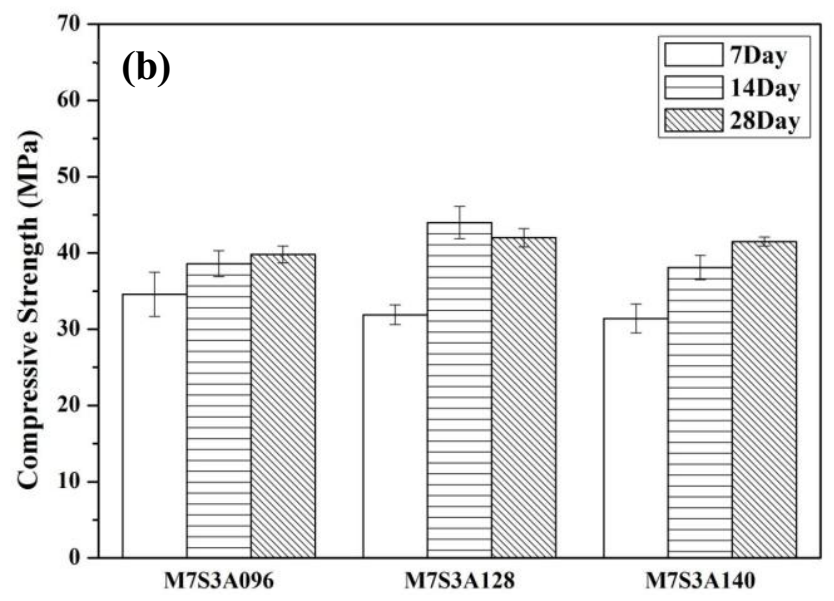

Fig. 4. Alkali solution different $\mathrm{SiO}_{2} / \mathrm{Na}_{2} \mathrm{O}$ molar ratio - (a) setting time (b) compressive strength. Marble $/$ BFS wt. $\%$ ratio $=70: 30$, Liquid $/$ Solid wt. $\%$ ratio $=0.4$.

\subsection{NMR analysis}

After 28 days curing, marble-based geopolymer (M7S3) sample was analyzed using Nuclear Magnetic Resonance Spectroscopy (NMR). By comparing with traditional coal fly ash-based geopolymer, as shown in Figure 5, it can be found that the $\mathrm{Q}_{4}{ }^{4}$ in fly ash based geopolymer was higher than that of in marble-based geopolymer. This is because the major element in coal fly ash is $\mathrm{Si}$, after geopolymeric reaction, coal fly ash can dissolve large amount of Si for forming $\mathrm{Q}_{4}{ }^{4}$. In marble-based geopolymer system, the main $\mathrm{Si}$ sources is BFS or sodium silicate, therefore only $15 \% \mathrm{Q}_{4}{ }^{4}$ was measured in the marble based geopolymer.

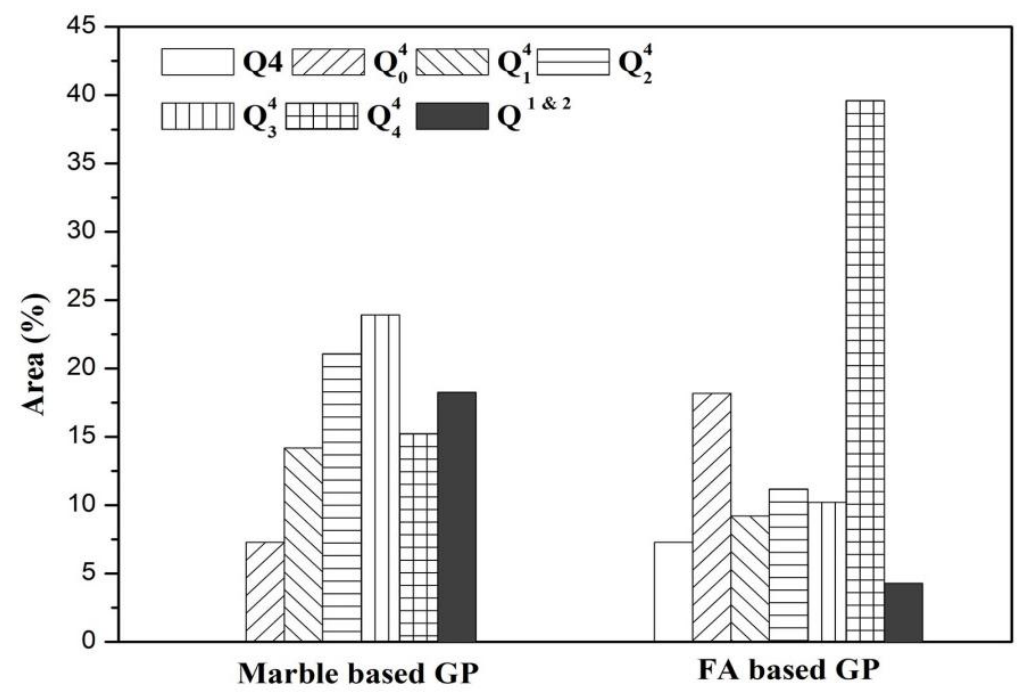

Fig. 5. ${ }^{29} \mathrm{Si}$ NMR analyze result Marble based GP: Marble / BFS wt. $\%$ ratio $=70: 30$, Alkali Solution $\mathrm{SiO}_{2} / \mathrm{Na}_{2} \mathrm{O}=1.28$, Liquid $/$ Solid wt.\% ratio $=0.4$.FA based GP: Coal fly ash $/$ BFS wt. $\%$ ratio $=70: 30$, Alkali Solution $\mathrm{SiO}_{2} / \mathrm{Na}_{2} \mathrm{O}=1.28$, Liquid / Solid wt.\% ratio $=0.4$. 


\section{Conclusions}

Marble and BFS based geopolymer was successfully developed in this study. After curing for 28 days, the compressive strength of marble-based geopolymer can reachs 42 60 MPa. The viscosity of geopolyme paste can be controlled between $1100 \sim 6700 \mathrm{mPa} \quad \mathrm{s}$, and the final setting time can be controlled between $40 \sim 120 \mathrm{~min}$. It is believed that the fabrication of marble-based geopolymer has great potential for engineering application.

\section{References}

1. D.L.Y. Kong, J.G. Sanjayan, Cem. Concr. Compos., 30, 986 (2008)

2. I. Lecomte, C. Henrist, M. Li'egeois, F. Maseri, A. Rulmont, R. Cloots, J. Eur. Ceram. Soc., 26, 3789 (2006)

3. P. Duxson, A. Fernandez Jimenez, J.L. Provis, G.C. Lukey, A. Palomo, J.S.J. Van Deventer, J. Mater. Sci., 42, 2917-2933 (2006)

4. IEA/OECD Key World Energy Statistics, (2015)

5. M. Schneider, M. Romer, M. Tschudin, H. Bolio, Cem. Concr. Res., 41, 642 (2011)

6. J.S.J. Van Deventer, J.L. Provis, P. Duxson, Miner. Eng., 29, 89 (2012) 